\title{
Main Fuel Cells Mathematical Models: Comparison and Analysis in Terms of Free Parameters
}

\author{
D. Bonanno, F. Genduso, R. Miceli, member IEEE, C. Rando
}

\begin{abstract}
This paper resumes the main mathematical models of Fuel Cells (PEM models). In particular, a comparison study of the various models introduced in the technical literature is presented and the dependency of the various model parameters is analyzed in different operating conditions. As the manifold of the model parameter is very wide and their determination is difficult, it is mandatory to introduce approximations and simplifications on which each model is based. The novelty of this work is the organization of the existing models in three categories with regard to the number of free parameters and to the dependency of such parameters on the different running conditions and the usage of a reference model in order to compare the difference between the latter once both in terms of fast execution of the simulation and care of the simulation results.
\end{abstract}

Index Terms-Fuel Cell, Mathematical modeling, Parameter Analysis

\section{INTRODUCTION}

Fuel Cells are today the object of research in different fields such as transportation, house feeding and automotive. In spite of the difficulties bounded to stocking, the usage of hydrogen as an energy vector has big advantages connected to high efficiencies and low environmental impact.

Another problem related to hydrogen is the production process in which the energy spent is higher than that released when the fuel is used for energy production. For this reason technologies of fuel cell are under investigation and they are increasing all over the world, in particular in the European Union, where the researches are investigating the potential of such technology in the static applications as for example those in the field of photovoltaic hybrid systems with electrolyzed and fuel cells.

Each fuel cell is characterized by its polarization curve in which the available voltage is tracked as a function of the current density $\left[\mathrm{A} / \mathrm{cm}^{2}\right]$. For purpose of analysis, suitable mathematical models have to be able to reproduce in the best way possible the real behavior of the stack.

In the technical literature various models have been presented e.g. [1]-[19],[4], and the very accurate paper [3] in which physical phenomena are investigated and modeled through partial derivatives differential equations. All these models are able to reproduce with different degrees the stack operations under different simplification hypotheses related to the number of free parameters. Free parameters are those being adjustable in order to reduces the difference between the simulation and the real behavior of the stack.

D. Bonanno, F. Genduso, R. Miceli, and C. Rando are with the DIEET - Dipartimento di Ingegneria Elettrica, Elettronica e delle Telecomunicazioni Università degli Studi di Palermo, email: genduso @dieet.unipa.it, miceli@dieet.unipa.it, cosimo_rando@dieet.unipa.it
The models presented in this paper include the modeling of physical phenomena and the related parameters even if, from a statistical point of view, these are not strictly necessary for a higher quality of the model. In this sense a black box approach, sometimes, can be considered suitable. The black box approach clearly excludes the understanding of physical phenomena insides the occurring in the cell. A black box model establish only a relation between inputs and outputs. Such and approach does not exclude the best fitting of the polarization curves.

However, in this paper, modeling of physical phenomena and their related parameters are considered in order to give models being helpful for designers who wants to predict, with numerical experiments, the electro-chemical dynamic, for example, when the load changes with different speed degrees and eventually hypothesize a design change in the cell layer.

The three fundamental models are classified as follows: ten parameter model; six parameter model; four parameter model.

In the following sections these three model are implemented in the MATLAB programming environment with reference to a NUVERA fuel cell stack with a rated power of $5.5 \mathrm{~kW}$. The different polarization curves are compared in order to verify how much the initial assumptions influence the models response. The fundamental parameters of the NUVERA stack are summarized in Table I.

\begin{tabular}{|c|c|}
\hline Parameter & Value \\
\hline \hline n (Number of cells) & 40 \\
\hline Active area of the cell & $500 \mathrm{~cm}^{2}$ \\
\hline Thickness of the membrane & $0.0051 \mathrm{~cm}$ \\
\hline Maximum current density & $0.4 \mathrm{~A} / \mathrm{cm}^{2}$ \\
\hline Equivalent conductivity of the protonic conduction & $0.08 \mathrm{~S} / \mathrm{cm}$ \\
\hline Maximum power & $5.5 \mathrm{~kW}$ \\
\hline
\end{tabular}

TABLE I

PARAMETERS OF THE NUVERA FUEL CELL

For the determination of the polarization curve, in each model a load variation have been simulated in a given time range (namely 20 seconds) leading the stack from a no load to a full load condition. The Authors start from the consideration that the ten parameter model is the most correct as the number of initial assumption is minimal.

\section{THE TEN PARAMETER MODEL}

The ten parameter model is based on the following initial assumptions:

- the chemical reaction in the polymeric membrane are instantaneous;

- the reactive gases are ideal. 
The voltage across the stack terminals is given by the following equation:

$$
v_{f c}=E_{N e r n s t}-v_{a c t}-v_{o h m}-v_{c o n}
$$

where $E_{n e r n s t}$ is the Nernst ideal voltage when losses are not considered in the process of electrical energy production; $v_{a c t}$ is the activation voltage drop; $v_{o h m}$ is the ohmic voltage drop; $v_{c o n}$ is the concentration voltage drop.

The Nernst voltage for given temperature, oxygen pressure, $p_{\mathrm{O} 2}$, and hydrogen pressure, $p_{\mathrm{H} 2}$, is given by the equation:

$$
\begin{aligned}
E_{\text {Nernst }}= & 1.229-0.85 \cdot 10^{-3}(T-298.15)+ \\
& +4.3 \cdot 10^{-5} T \cdot\left[\ln \left(p_{H 2}\right)+\frac{1}{2} \ln \left(p_{O 2}\right)\right]
\end{aligned}
$$

For the activation voltage drop the used expression is [1], [2], [7], [8], [15], [19]:

$$
v_{A c t}=-\left[\xi_{1}+\xi_{2} T+\xi_{3} \ln \left(C_{O 2}\right)+\xi_{4} T \ln \left(i_{f c}\right)\right]
$$

in which: $i_{f c}$ is the stack current [A]; $T$ is the stack temperature $[\mathrm{K}] ; \xi_{1}=-0,948$; and $\xi_{2}=0,00286+0,0002 \ln (A)+$ $\left(4,3 \cdot 10^{-5}\right) \ln \left(C_{H 2}\right), \xi_{3}=7.6 \cdot 10^{-5}, \xi_{4}=-1.93 \cdot 10^{-4}$ are known coefficients [1], [7][1], [7], in which $C_{H 2}$ is the cathode hydrogen concentration in $\mathrm{mol} / \mathrm{cm}^{3}$ equal to:

$$
C_{H 2}=\frac{p_{H 2}}{R T}
$$

$A$ is the cell area, $C_{O 2}$ is the oxygen concentration on the cathode in $\mathrm{mol} / \mathrm{cm}^{3}$ determined by the following expression:

$$
C_{O 2}=\frac{p_{O 2}}{5.08 \cdot 10^{6} \exp (-498 / T)}
$$

The ohmic voltage drop [7], [15] are given by:

$$
v_{o h m}=i_{f c}\left(R_{m}+R_{c}\right)
$$

where: $R_{m}$ is the equivalent resistance of the electron flow:

$$
R_{m}=\frac{\rho_{m} L}{A}
$$

in which $L$ is the thickness of the membrane, $A$ is the membrane active area and $\rho_{m}$ is the resistivity defined by:

$$
\rho_{m}=\frac{18.61\left[1+0.03\left(i_{f c} / A\right)+0.062(T / 303)^{2}\left(i_{f c} / A\right)^{2.5}\right]}{\left[\psi-0.634-3\left(i_{f c} / A\right)\right] \exp \left(4.18 \frac{T-303}{T}\right)}
$$

where $\psi$ is a characteristic parameter depending on the cell type. The exponential therm is the thermal correction coefficient if the operating temperature of the cell is not equal to $30 \mathrm{C}$

$R_{c}$ is the proton resistance considered as constant. The last voltage drop terms are related to the concentration and are defined by the expression [1], [7], [8]:

$$
v_{\text {conc }}=-m \exp (n i)
$$

where $m$ and $n$ are known coefficients, $i$ is the stack current density $\left[\mathrm{A} / \mathrm{cm}^{2}\right] . m$ is bounded to conductivity while $n$ depends on the porosity of the gases permeation layer. The $m$ value is calculated according to the stack temperature to the basis of the following equations:

$m=-1.1 \cdot 10^{-4}-1.2 \cdot 10^{-6}(T-273.15)$ for $T>312.15 K$

$m=3.3 \cdot 10^{-4}-8.2 \cdot 10^{-5}(T-273.15)$ for $T<312.15 K$

$$
n=8.3 \cdot 10^{-3} \mathrm{~cm}^{2} / \mathrm{mA}
$$

The hydrogen and oxygen partial pressures are calculated with the following relations:

$$
\begin{aligned}
p_{H 2} & =0.5 p_{H 20}^{s a t}\left[\exp \left(-\frac{1.63 i / A}{T^{1.334}}\right) \frac{p_{a}}{p_{H 2 O}^{s a t}}-1\right] \\
p_{O 2} & =p_{H 20}^{s a t}\left[\exp \left(-\frac{4.192 i / A}{T^{1.334}}\right) \frac{p_{c}}{p_{H 2 O}^{s a t}}-1\right]
\end{aligned}
$$

- where $p_{a}$ is the anode pressure (namely $1 \mathrm{~atm}$ )

- $p_{c}$ is the cathode pressure (namely $1 \mathrm{~atm}$ )

- $p_{H 2 O}^{s a t}$ is the water saturation pressure obtained by:

$$
\begin{aligned}
\log _{10} p_{H 2 O}^{\text {sat }}= & -2.18+2.95 \cdot 10^{-2} T_{c}+ \\
& -9.18 \cdot 10^{-5} T_{c}^{2}+1.441 \cdot 10^{-7} T_{c}^{3}
\end{aligned}
$$

in which $T_{c}$ is equal to: $T-273.15$.

In the ten parameter model the stack temperature is considered as variable. From the thermodynamic model of a PEM the temperature variation is subject to the following differential equation [2]:

$$
C_{t} \frac{d T}{d t}=i\left(E-V_{\text {cell }}\right)-H\left(T-T_{f}\right)
$$

where: $C_{t}$ is the thermal capacity of the whole fuel cell volume; $H$ is the thermal transmission coefficient for the whole fuel cell surface; $T_{f}=30+273.15$

This equation has been solved with the aim of the SIMULINK package taking the initial condition ( $T_{0}$ environmental temperature) into account. The fuel cell exhibits a transient known as charge "double layer phenomenon". Each time two different material enter in contact, a charge flow between them begins. This layer behaves electrically as a capacitor whose charge changes following the load request, but with a delay. When the stack current changes some time has to be spent before the over voltages due to activation and concentration exhibit. In this case only the ohmic voltage drop follows the current pattern. Figure 1 shows the cells equivalent network [6], [9], [10], [11], [19].

with reference to Fig. 1, $R_{o h m}$ is the ohmic resistance; $R_{\text {conc }}$ is the concentration resistance; $R_{a c t}$ is the activation resistance; $C$ is the capacitor that model the charge double layer phenomenon.

the differential equation for the dynamic voltage $v_{d}$ is: 


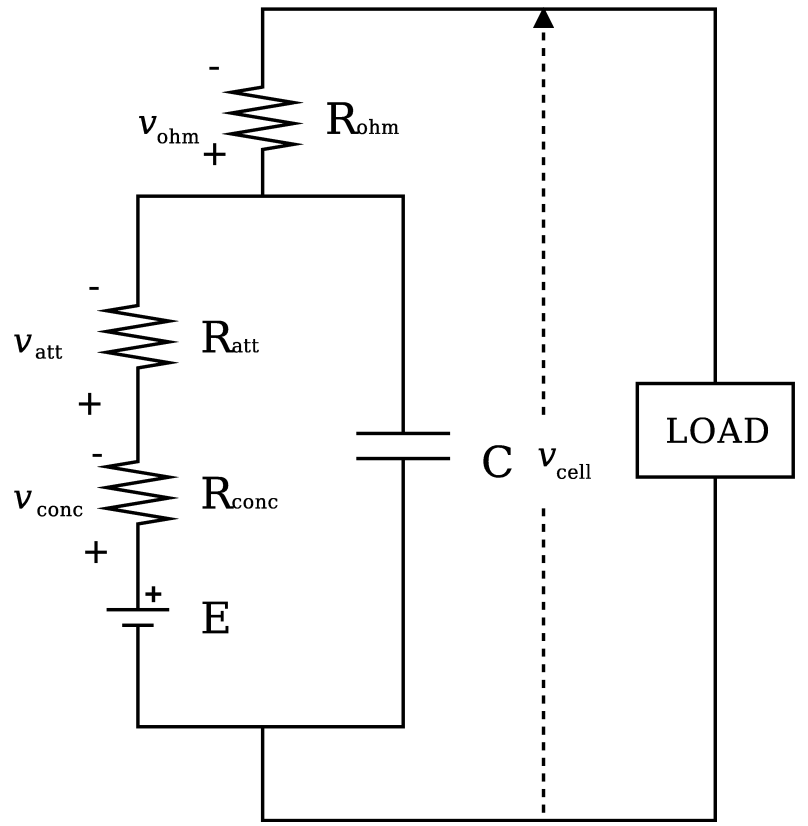

Fig. 1. Equivalent network of the cell during the transient

$$
\frac{d v_{d}}{d t}=\frac{i}{C}-\frac{v_{d}}{\tau}
$$

The capacitor value is estimated to be in the range 2,5 - 3 $\mathrm{F} \mathrm{C}$; $\tau$ is the time constant defined by:

$$
\tau=\frac{C\left(v_{a c t}+v_{\text {conc }}\right)}{i}
$$

The cell voltage is the defined by:

$$
v_{\text {cell }}=E_{\text {Nernst }}-v_{o h m}-v_{d}
$$

All the differential equations may be easily solved with the help of the SIMULINK packages. The results may be then compared with experimental data. The same SIMULINK package allows the determination of the polarization curve.

As an example, figure 2 shows the polarization curve for the ten parameter model assumed as the reference model.

For the determination of the polarization curve the simulation is started with a null current growing up till to the maximum value of the NUVERA stack current (200A).

\section{THE SIX PARAMETER MODEL}

In the six parameter model the initial assumption are:

- the chemical reactions in the polymeric membrane are instantaneous;

- the temperature inside the stack is constant and homogeneous;

- the partial pressures of the components under reaction are constants.

The last two assumptions make this model different from the ten parameters one, resulting, for this reason, more simple. Obviously, the simulated behavior of the stack result to be a bit different than that of the previous model. The Tafel equation

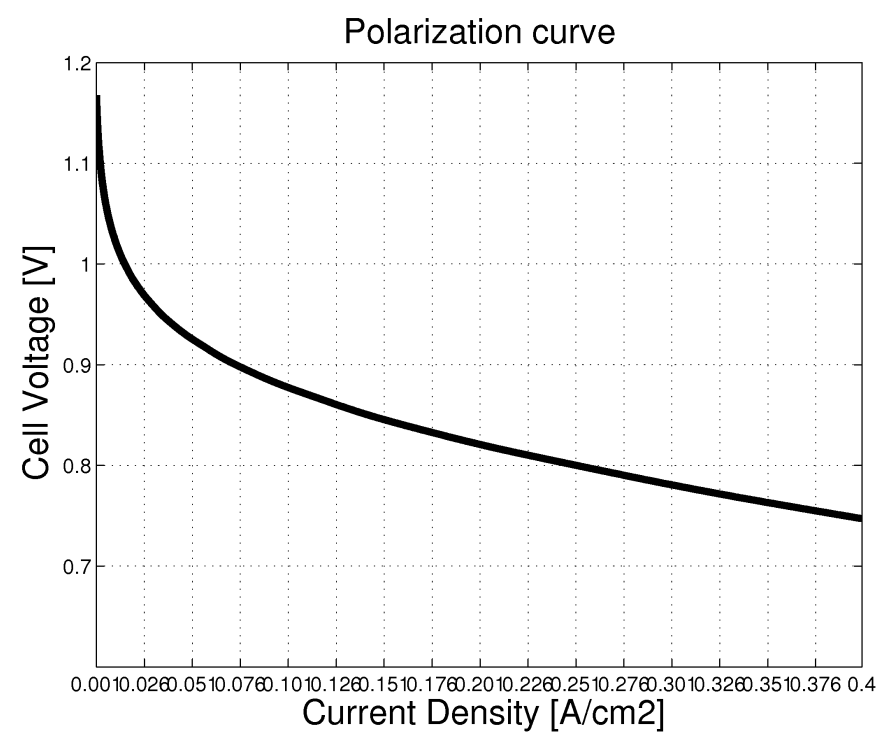

Fig. 2. Polarization curve of the ten parameter model.

describes the bound between the activation over voltage and the current density $i$ [7], [8]:

$$
v_{a c t}=A \ln \left(\frac{i}{i_{0}}\right)
$$

where $A$ is a constant, $i_{0}$ is the exchange current density. In particular $A$ has practically high values for slow reactions so, as the slowest reaction happens near the cathode, the voltage drop due to activation is concentrated, above all, near the cathode itself. the $A$ constant is given by:

$$
A=\frac{R T}{2 \alpha F}
$$

where $\alpha$ is the charge transmission coefficient, i.e. the part of electrical energy used to change the speed of chemical reaction. Its value depends mainly on the type of reaction involved and on the electrodes material. Its range varies from 0 to $1 ; T$ is the cell temperature (in kelvin). The higher is the temperature the higher is the value assumed by $A$ and the activation losses; $R$ is the universal gases constant; $F$ is the Faraday constant.

The voltage drop due to the ohmic effect is proportional to the cell current according to the Ohm law [7]:

$$
v_{o h m}=R_{o h m} i_{f c}
$$

where $i_{f c}$ is the cell current in $A, R_{o h m}$ is the internal resistance.

In the most part of fuel cells this resistance is due to the electrolyte. In each case, also the connection resistance must be considered (mainly the cells are cascade connected).

The internal resistance depends on the membrane humidity too and on the cell temperature.

Some authors have demonstrated that this internal resistance depends on the conductivity $\sigma_{m}$ of the cell according to the law: 


$$
R_{o h m}=\frac{t_{m}}{\sigma_{m}}
$$

where $t_{m}$ is the thickness of the membrane.

A relation allowing the calculation of the membrane conductivity is

$$
\sigma_{m}=b_{1} \exp \left[b_{2}\left(\frac{1}{303}-\frac{1}{T_{f c}}\right)\right]
$$

where $b_{2}$ is empirically determined and $b_{1}$ is determined by:

$$
b_{1}=b_{11} \lambda-b_{12}
$$

In this equation $b_{11}$ and $b_{12}$ are also empirically determined and $\lambda$ is the stoichiometric speed. So the internal cell resistance will be:

$$
R_{o h m}=\frac{t_{m}}{b_{1} \exp \left[b_{2}\left(\frac{1}{303}-\frac{1}{T_{f c}}\right)\right]}
$$

A simple relation allowing to determine the voltage drop due to concentration loss is:

$$
v_{\text {con }}=i\left(c_{2} \frac{i}{i_{\text {max }}}\right)^{c_{3}}
$$

where $c_{2}$ and $c_{3}$ are constants depending on temperature and on the partial pressures of the reactants to be experimentally determined, $i$ is the current density in $\left[A / \mathrm{cm}^{2}\right]$ while $i_{\max }$ is the maximum reachable value. The coefficient $c_{2}$ is calculated by two equations whose choice depends on the saturation pressure:

$$
\begin{aligned}
& c_{2}=\left(7.16 \cdot 10^{-4} T_{s t}-0.622\right) \cdot\left(\frac{p_{O 2}}{0.1173}+p_{\text {sat }}\right)+ \\
&+\left(1.68-1.45 \cdot 10^{-3} T_{s t}\right) \\
& \text { if } \frac{p_{O 2}}{0.1173}+ p_{\text {sat }}<2 \mathrm{~atm} \text { and } \\
& c_{2}=\left(8.66 \cdot 10^{-5} T_{\text {st }}-0.068\right) \cdot\left(\frac{p_{O 2}}{0.1173}+p_{\text {sat }}\right)+ \\
&+\left(0.54-1.6 \cdot 10^{-4} T_{\text {st }}\right) \\
& \text { if } \frac{p_{O 2}}{0.1173}+p_{\text {sat }}>2 \mathrm{~atm}
\end{aligned}
$$

The evaluation of the saturation pressure is executed with the following relation:

$p_{\text {sat }}=1.508 \cdot 10^{-6} T_{s t}^{4}-0.0018 T_{s t}^{3}-179.6 T_{s t}^{2}+1.428 \cdot 10^{4}$

Table II contains the rating of the six parameter model.

\section{THE FOUR PARAMETER MODEL}

The last examined model has big simplification in comparison to the previous. These allows a simpler computer simulation. The initial assumptions are:

Reacting gases uniformly distributed;

constant temperature;

constant pressure for the reactants.

A further adopted hypotheses is the constance of the resistance as the stack temperature varies.

\begin{tabular}{|c|c|}
\hline Parameters & Values \\
\hline \hline$b_{11}$ & 0.005139 \\
\hline$b_{12}$ & 0.003243 \\
\hline$b_{2}$ & 350 \\
\hline$\alpha$ & 0.205 \\
\hline T (stack temp.) & $315.15 \mathrm{~K}$ \\
\hline$c_{3}$ & 2 \\
\hline
\end{tabular}

TABLE II

SIX PARAMETER MODEL COEFFICIENTS

\begin{tabular}{|c|c|}
\hline Parameter & Value \\
\hline \hline$n$ (number of cells) & 40 \\
\hline$K_{1}$ & 0.035 \\
\hline$K_{2}$ & 0.092 \\
\hline$b$ & 1.36 \\
\hline$T$ (stack temp.) & $315.15 \mathrm{~K}$ \\
\hline$i_{0}$ & $5 \cdot 10^{-6}$ \\
\hline$C_{e q}$ & $0.08 \mathrm{~S} / \mathrm{cm}$ \\
\hline
\end{tabular}

TABLE III

FOUR PARAMETER MODEL COEFFICIENTS

The single components of the voltage drop are:

$$
\begin{gathered}
v_{a c t}=b \ln \left(\frac{i_{f c}}{i_{0}}\right) \\
v_{o h m}=R_{o h m} i_{f c} \\
v_{c o n c}=K_{1} i_{f c} e^{K_{2} i_{f c}}
\end{gathered}
$$

where: $b, K_{1} K_{2}$ are known constants; $i_{f c}$ is the current density of the stack in $A / \mathrm{cm}^{2} i_{0}$ is the activation current depending on the used catalyst. In table III the known model parameter are reported.

\section{MODELS COMPARISON}

The polarization curves obtained via the previously discussed models are compared as shown in figure 3 with the aim to verify how much the initial assumptions may influence the polarization curve pattern.

The ten parameter model can be assumed as a reference model in virtue of the minimal number of initial simplificative assumptions, because its behavior is closer to the real one of the stack. In this way the difference between of the six and the four parameter model can be evaluated.

it is so possible to evaluate in what operating conditions the latter two models can be considered as acceptable.

Figures 4, 5, and 6 report the differences between the polarization curves in the zones where each of the three voltage drops are significant.

\section{PARAMETRIC ANALYSIS OF THE POLARIZATION CURVES}

Figures 7 and 8 show the pattern of the differences between the ten parameter model assumed as reference and the six and four parameter model. In the case of complex systems simulations, as for example an automotive drive fed by fuel 


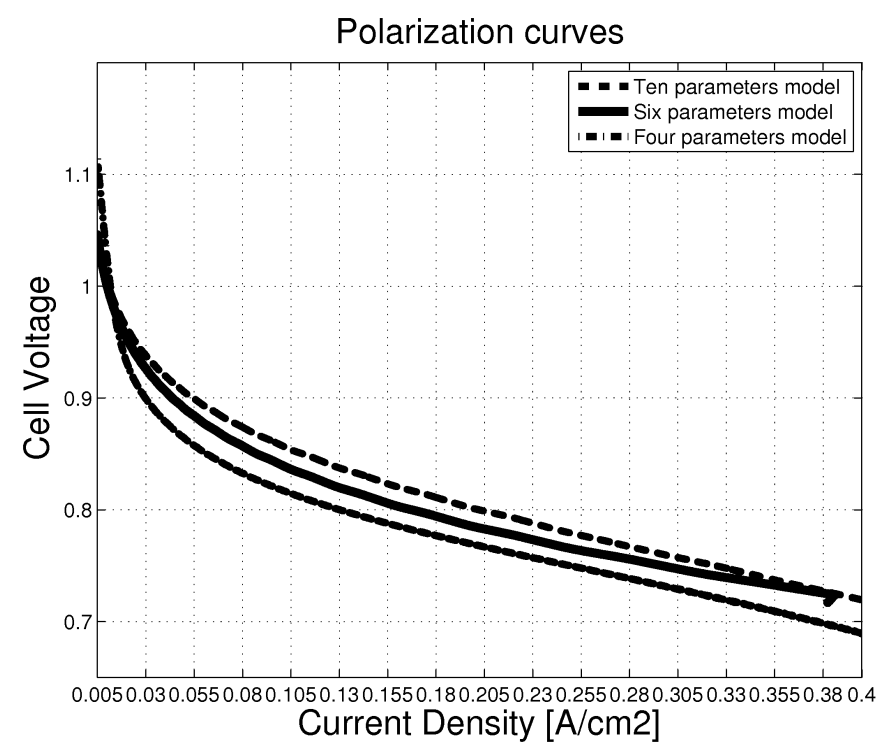

Fig. 3. Comparison between the polarization curves of the three main models

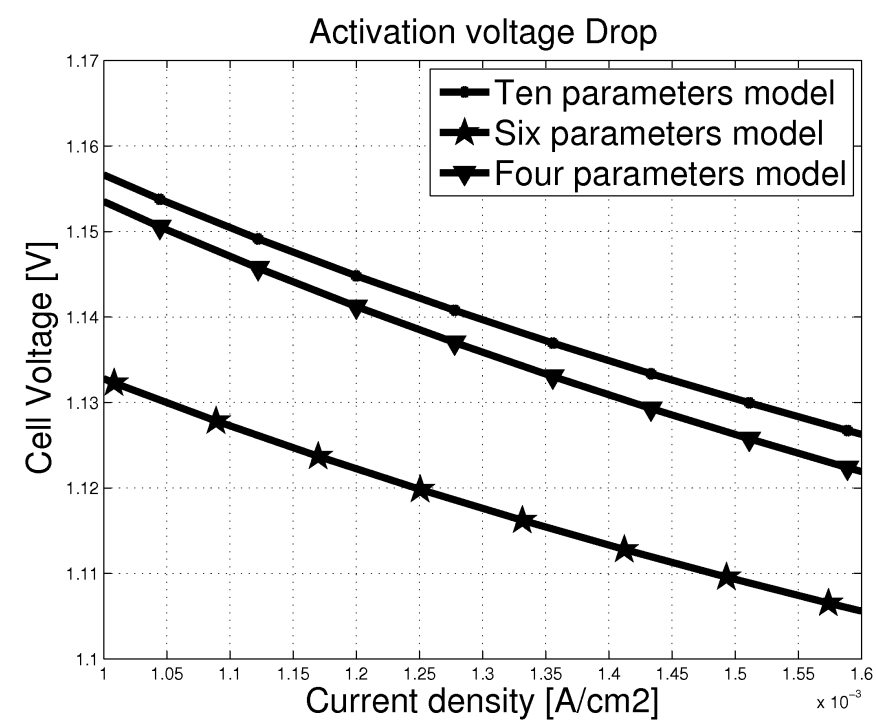

Fig. 4. Comparison in the polarization curves of the activation voltage drops

cells in which the models of brushless machines, power converters are to be used it is mandatory to simplify as possible the mathematical model of each component and device of the system in order to gain a good trade off between simulation speed and care of the results.

The difference is maximized, at the extent of about $2 \%$, for current values close to $100 \mathrm{~A}$, i.e. in the zone for which the ohmic voltage drops are more relevant. On the contrary the difference is minimal at a no load condition.

At the tail of the polarization curve the concentration voltage drops are relevant and the extent of the difference amount to about $1 \%$. These result puts in evidence that the hypothesis of constant temperature maximizes the difference mainly at the center of the polarization curve. However the error may be considered acceptable in many cases.

When the fuel cell works close to the low currents range the

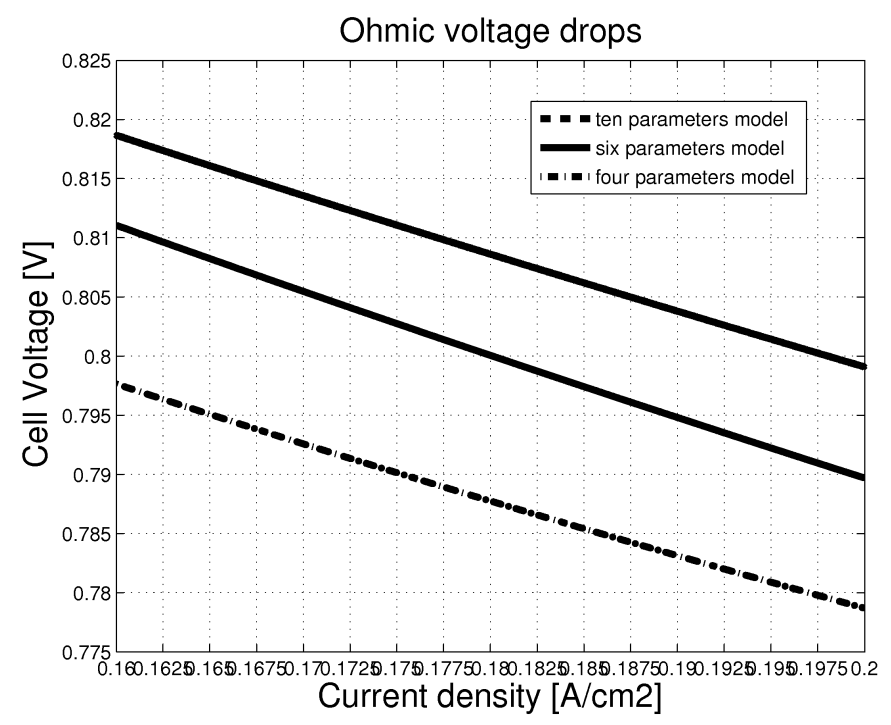

Fig. 5. Comparison in the polarization curves of the ohmic voltage drops

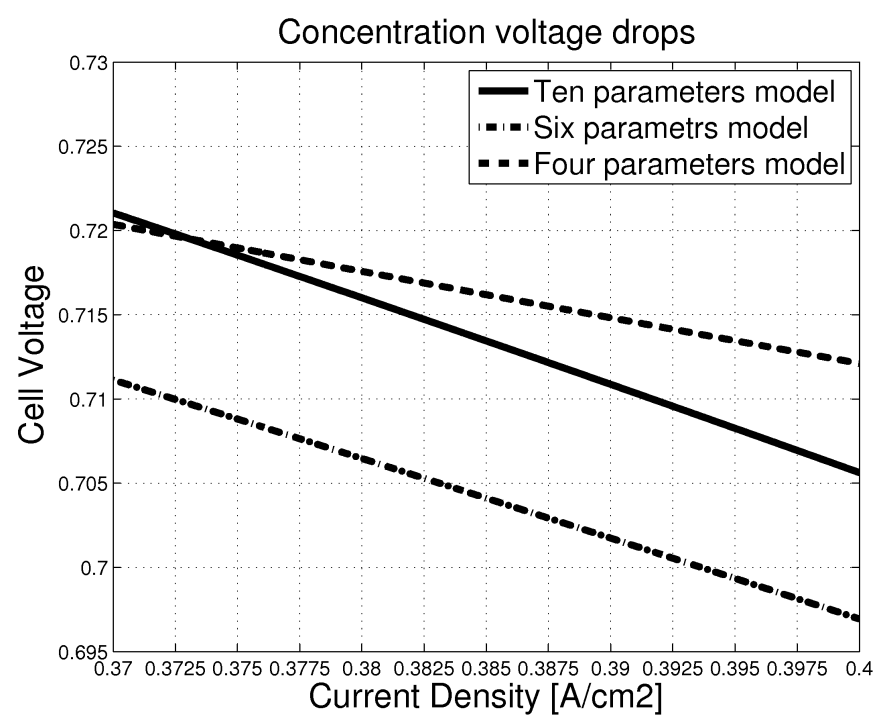

Fig. 6. Comparison in the polarization curves of the concentration voltage drops

ten parameters and the six parameter model may be considered almost equivalent.

Because of the higher number of initial assumptions, clearly, the gap of the four parameter model respect to the reference one is higher. The highest gap, close to $4 \%$, appears always in the center range of the polarization curves. In the low current range the error reach its minimum values (about 2\%) and, finally, in the high current range the error may be considered constant (about 3.5\%).

The increased gap in the center of the polarization curve is due to the additional hypotheses for which the membrane resistance is considered constant, as versus the temperature, as versus the stack current. This is the reason why the number of the model equations is reduced. 
Deviation between ten and six parameters model

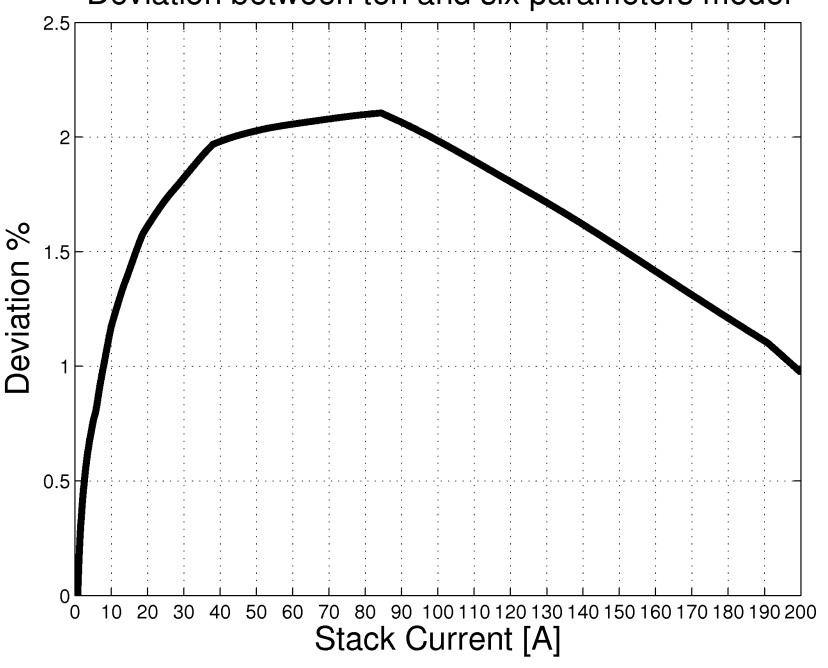

Fig. 7. Difference between the ten parameter model and six parameter model polarization curve

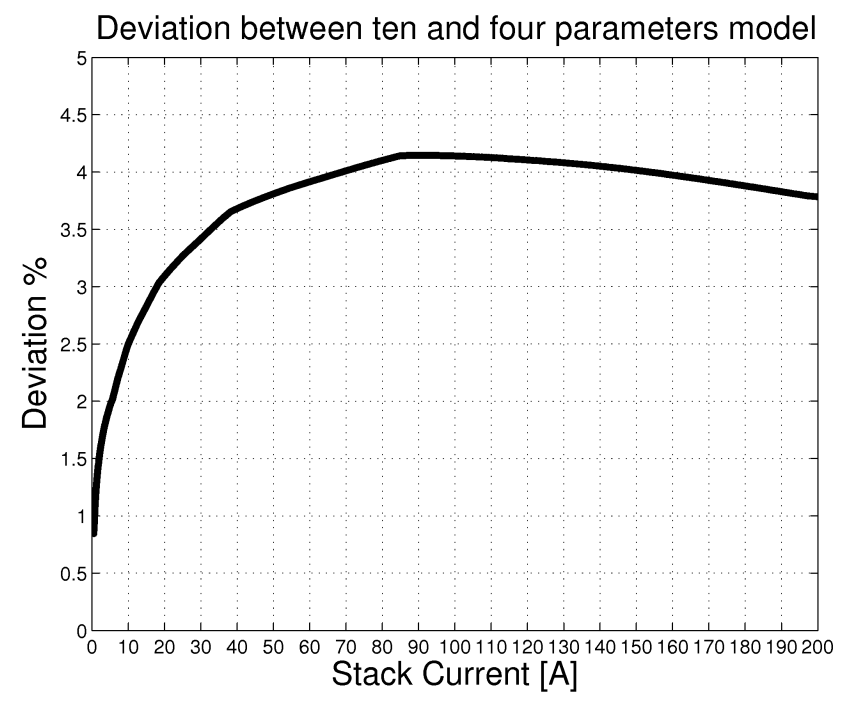

Fig. 8. Difference between the ten parameters and the four parameters model

\section{CONCLUSIONS}

This paper has presented the three main mathematical models available in the technical literature. The three models are distinguished on the basis of the number of free parameters on which it is possible to make some modifications in order to increase the precision of the model results. As a matter of fact, the lower is the parameter number, the easier are the simulations, but, at the same time, the gap respect to the real behavior of the real stack increases.

In the case of complex systems simulation a simplification of the model is mandatory for the sake of their fast execution but the care about precision of the results cannot be avoided. A trade off between the precision of the results and the speed in execution is to be found.

The simulation results presented in this paper and referred to the six and four parameter model, by using the ten parameter model, as a reference one, have shown as the maximum error in the polarization curves is gotten at the center of the current range. The four parameter model exhibit an higher gap respect to the six parameter model.

In conclusion the usage of the six parameter model is preferable in most cases and situations.

\section{ACKNOWLEDGMENTS}

This work was supported by MIUR (Italian Ministry of Instruction, University and Research) and by SDESLAB (Sustainable development and Energy Saving Laboratory) of the University of Palermo and was partially supported by the project BeyWatch IST-223888 funded by the European Community.

\section{REFERENCES}

[1] Marcos V. Moreira, Gisele E. da Silva, "A pratical model for evaluting the performance of proton exchange membrane fuel cells", Renewable Energy 34 (2009) pp 1734 - 1741;

[2] Yancheng Xiao, Kodjo Agbossou, "Interface Design and Software Devolopment for PEM Cell Modeling based on Matlab/Simulink Environment", World Congress on Software Software Engineering IEEE 2009;

[3] Atilla Biyakoglu "Review of Proton Exchange Membrane Fuel Cell Models" International Journal of Hydrogen Energy, Vol. 30 Issue 11 (2005) pp. $1181-1212$.

[4] Kristina Haraldsson, Keith Wipke "Evaluating PEM Fuel Cell System Models" Journal of Power Sources, Vol. 126, Issues 1-2, 16 Febuary 2004, pp 88-97

[5] P. Buasri, Z. M. Salameh, "An Electrical Circuit Model for A Proton Exchange MembraneFuel Cell (PEMFC), IEEE 2006;

[6] J. B. Jia, Y. T. Cham, Y. Wang, Frank Lewis, "The electrical Dynamic Response Study of PEMFC as a Backup Power Supply", 2007 IEEE International Conference on Control and Automation Guangzhou, CHINA - May 30 to June 1, 2007;

[7] Dallia Morsi Ali, "A Simplified Dynamic Simulation Model (prototype) for a Stand - AlonePolymer Electrolyte Membrane (PEM) Fuel Cell Stack", 2008 IEEE;

[8] D. Morsi Ali, S.K. Salman, "Investigation Into Modelling Of A Fuel Cell Stack System"IEEE 2004;

[9] J. Jia, Q. Li, Y. Wang, Y. T. Cham, M. Han, "Modeling and Dynamic CharacteristicSimulation of a Proton Exchange Membrane Fuel Cell", IEEE Transactions on Energy Conversion, Vol. 24, NO. 1, March 2009;

[10] Mathias Purmann, Günter Heideck, Zbigniew Styczynski, "Extendend Model for the Dynamic simulation of a PEM fuel cell in stationary applications", Institute of Electric Power System, Magdeburg, Germany, 2004;

[11] Caisheng Wang, M. Hashem Nehrir, Steven R. Shaw, Dynamic Models and Model Validation for PEM Fuel Cells Using Electrical Circuits", IEEE Transactions on energy Conversion, Vol. 20, NO. 2, June 2005;

[12] R. Tirnovan, A. Miraoui, S. Giurgea, "Modeling and Analysis of a High Pressare Operting Fuel Cell Hydrogen/Air system, UTBM laboratory, University of Technology of Belfort - Montbeliard, IEEE 2007;

[13] Maher A. R. Sadiq Al - Baghdadi, "Modelling of proton exchange membrane fuel cell performance based on semi - empirical equation", Renewable Energy 30 (2005) 1587/1599;

[14] R. Liga, " Sistema di propulsione per automotive dotato di azionamento con motore brushless a magneti permanenti alimentato con PEM Fuel Cells", Università degli studi di Palermo, A.A: 2003 - 2004;

[15] Salvatore P. Cicconardi, Maurizio Granati, "Simulazione stazionaria e dinamica di un sistema cogenerativo da $5 \mathrm{Kw}$ e supporto alla progettazione", ENEA, Report RSE/ 2009179 (in italian);

[16] Fuel Cell, www.ipassnet.it;

[17] V. Di Dio, D. La Cascia, R. Liga, R. Miceli, "Integrated Matematica Model of proton Exchange Membrane Fuel Cell Stack (PEMFC) with Automotive Synchronous Electrica Power Drive", Proceedings of the 2008 International Conference on Electrical Machines;

[18] S. Pedrazzi, "Modellizzazione Sistema Ibrido ad Idrogeno Solare", B.Sc. thesis, Università digli studi di Modena e Reggio Emilia, 2006 - 2007;

[19] P.R. Pathapati, X. Xue, J. Tang, "A new dynamic model for predicting transiet phenomena in a PEM fuel cell systema", Renewable Energy 30 (2005) $1-2$ 